\title{
Neoliberalizm ve Yerel Yönetişim Bağlamında Kamu Özel Sektör İşbirliklerinin Yerel Girişimcilik Üzerine Etkileri*
}

\author{
Burcu GEDİZ ORAL ${ }^{* *} \quad$ Tuğba ARPAZLI FAZLILAR ${ }^{* * *}$
}

\begin{abstract}
$\ddot{O} Z$
Neoliberalizmin yükselişi ile yerel girişimcilik olarak tanımlanan yeni bir yönetim düzeninin ortaya çıması arasında doğrudan bir ilişki vardır. Yeni yerel politika, kamu faaliyet alanının sinırlandırllması ve uluslararası sermaye hareketliliğinin artmasından etkilenmektedir. Bu yüzden sermaye birikimini teşvik etmek ve yerelin karşılaştırmalı üstünlüklerini artırmak için dönüşüm çă̆risında bulunulmaktadır. Girişimci yönetişim biçimlerine geçiş, kamu hizmetleri tedariğinde değişimi ve yeni sosyal aktörleri yönetim alanına dâhil etmek için yönetişimin yerel uygulamalara ve düzenlemelere indirgenmesi anlamlarına gelmektedir. Yerel hizmetlerde hem kamu özel sektör işbirliklerine (KÖSI) hem de girişimciliğin kabiliyetine olan ilgi artmaktadır. Bu çalışmada KÖSI'lerin yerel girişimcilik için önemi ve KÖSİ yönetim boyutlarının karmaşılklı̆̆ analiz edilmiştir. Yerel projeler, farklı beklentileri olan birden fazla oyuncuyu içerdiklerinden oldukça karmaşıktır. Bu durum yerel veya bölgesel düzeyde yönetişim rejimlerinin varlığını gerektirmektedir. KÖSI'ler finansman programlarını optimize etmek için yerel otoriteleri, finans sektörünü ve kar amacı gütmeyen kuruluşları bir araya getirirler. Bu nedenle bu işbirlikleri yerel finansmanın etkili yollarından biridir. KÖSi'ler, yerel işletmeler tarafindan kolayca erişilebilen ve onların ihtiyaçlarına göre uyarlanmış destek mekanizmaları sağlamaktadır. Bu çalışma, çok oyunculu yönetişimin karmaşıklıklarının yerel projelerin uygulanmasını nasıl etkilediği üzerine teorik bir bakışla odaklanmaktadir.
\end{abstract} İşbirlikleri

Anahtar Kelimeler: Girişimcilik, Yerel Girişimcilik, Girişimci Şehirler, Kamu Özel Sektör

JEL Sinıflandırması: L26, R11, L32

\section{The Effects Of Public Private Partnerships On Local Entrepreneurs In The Context Of Neoliberalism And Local Governance}

\begin{abstract}
There is a direct relationship between the rise of neoliberalism and the emergence of a new system of governance defined as local entrepreneurship. The new local policy is affected by the limitation of the public sector and the increase in international capital mobility. Therefore, it is called for transformation to promote capital accumulation and to increase the comparative advantage of the local.Transition to forms of entrepreneurial governance means that reducing governance in public services and reducing governance to local practices and local regulations for involve new social
\end{abstract}

\footnotetext{
* Bu çalışma 10. Uluslararası Girişimcilik Kongresi’nde (25-26.04.2019 Manisa) sunulan "Yerel Girişimcilik, Girişimci Şehirler Kamu Özel Sektör İş birlikleri” adlı çalışmanın gözden geçirilmiş genişletilmiş halidir.

** Doç. Dr., Manisa Celal Bayar Üniversitesi, Uygulamalı Bilimler Fakültesi, Şehit Prof. Dr. İlhan Varank Yerleşkesi, burcu.gediz@bayar.edu.tr, ORCID bilgisi: 0000-0001-7096-9288

*** Araş. Gör. Tuğba Arpazlı Fazlılar, Manisa Celal Bayar Üniversitesi, Uygulamalı Bilimler Fakültesi, Şehit Prof. Dr. İlhan Varank Yerleşkesi, t.arpazli@ hotmail.com, ORCiD bilgisi 0000-0001-8838-8959
} 
actors in the sphere of government. Local services in both the public private partnerships (PPPS) as well as the ability is increasing interest in entrepreneurship. In this study analized that the importance of PPPs for local entrepreneurship and the complexity of the PPPs management dimensions. Local projects are quite complex because they contain more than one actor with different expectations. This requires the existence of governance regimes at the local or regional level. PPPs bring together local authorities, the financial sector and non-profit organizations to optimize their financing programs. Therefore, these cooperation is one of the effective ways of local financing. PPPs provide support mechanisms that are easily accessible by local businesses and adapted to their needs. This study focuses on a theoretical view of how complexity of multi-player governance affects the implementation of local projects.

Key Words: Entrepreneurship, Local Entrepreneurship, Entrepreneurial Urbanism, Public Private Partnerships

JEL Classification: L26, R11, L32

\section{GíRIŞ}

Yerel projeler, farklı beklentileri olan birden fazla oyuncuyu içerdiklerinden oldukça karmaşıktır. Bu durum yerel veya bölgesel düzeyde yönetişim rejimlerinin varlığını gerektirmektedir. Yerel yönetimler, çeşitli politika yapıcılık seviyelerinin karmaşıklı̆̆ıla başa çıkma stratejisini belirlemek durumundadır. Her yönetim, uygulama yörüngesinde, uzun veya kısa, başarılı veya başarısız kendine özgü bir deneyime sahiptir. Genellikle kamu özel sektör işbirlikleri (KÖSI) alternatif bir finansman aracı olarak kamu hizmet arzında kullanılmaktadır. Bu çalışma, çok oyunculu yönetişimin karmaşıklıklarının yerel projelerin uygulanmasını nasıl etkilediği üzerine odaklanmaktadır. Amaç, makro düzeydeki kurumsal bağlamın projenin başarısını nasıl etkilediğini göstermek ve çok oyunculu yönetişimin zorluklarını analiz etmektir.

Neoliberal yeniden yapılanma sürecinin politik ekonomisi, yeni üretim gruplarını, altyapıyı, ulaşımı ve iletişim ağlarını, işbölümünü, çeşitli bölgesel stratejileri teşvik etmeye yönelik politikalarla kanalize edilmiştir. $\mathrm{Bu}$ süreçler, çeşitli aktörler, ittifaklar ve kuruluşlarla birlikte kurumsal uygulamalar ve düzenleyici rejimler yeniden gözden geçirilmiştir (Jessop, 2002). Bu nedenle şehirler, yalnızca üretim yeri değil aynı zamanda insanların, emtiaların, finansın, fikirlerin ve kurumsal kapitalizmin iktidarla birleştiği bir yer olarak küresel ağa bağlanmıştır. Bu şartlar altında lojistik olarak, kent merkezleri; küresel finansal ve üretim zincirleri, hizmet arzı, ihracat merkezleri, finans, sağlık, eğitim, kültür ve spor gibi ekonomik faaliyetlerin merkezi olarak ortaya çıkmıştır. Bilgi, iletişim, finans ve altyapı yoluyla bu küresel ağlar temel olarak sermaye birikimi ve dolaşım için potansiyel bir temel oluşturmaktadır (Banerjee-Guha, 2010).

1980'lerden sonra devlet kontrolünün sınırlandırılması, kamu kesiminin küçültülmesi, refah programlarının azaltılması ve uluslararası sermaye hareketliliğinin artmasından etkilenen yeni kentsel politika, sermaye birikimini teşvik etmek ve kentin karşılaştırmalı avantajlarını artırmak için küresel bir içe yatırım ekonomisine dönüşüm çağrısında bulunmaktadır. Bu politika, "merkezi yönetimden" "girişimci yönetişim"e doğru bir kayma gerektirmiştir. Böylece belediye hükümetin, kentsel kalkınma politikasını uygulayıcısı olmak yerine aktif bir taraf olarak kentsel gelişimde kilit oyuncu haline gelmektedir. Bu eğilim, maliyetlerin azaltılması şeklinde bir şehir girişimciliği biçiminde ortaya çıkmış, 
belediyeler, yönetim maliyetlerini düşürmek için çeşitli tedbirler almak zorunda kalmıştır. Çünkü bütçeleri giderek daha kısıtlı olmuştur (Taşan Kok, 2010). 1990'larda serbest piyasa ilkesi gereği, devletin düzenleyici fonksiyonu, yaşamlarını belirli bir girişimcilik formu vermeye teşvik edilen sorumlu ve rasyonel bireylere kaydırdığ yerel yönetimlerin politik gündemlerinde egemen olmuştur (Swyngedouw, 2005).

Küreselleşen ekonomide, belirsiz, rekabet eden ve dinamik hedeflerle görevli kamu sektörü kuruluşları, özel aktörlerle karmaşık ve sözleşmeye dayalı ortaklıklar kurarak hizmet teslimi üzerinde tam kontrol uygulama yeteneklerini giderek sınırlamaktadırlar. Hükümet ve özel sektör arasındaki bu geniş ilişkiler, 21. yüzyılın Yeni Kamu Yönetimi (YKY) olarak bilinen, giderek artan oranda parçalanmış ve belirsiz nitelikte kamu yönetiminin bir özelliğidir. Bu paradigmada KÖSI'ler, kamu sektörü kurumlarının proje teslimi için üçüncü tarafları harekete geçirmek, proje yaşam döngüsü boyunca ilgili paydaş ağlarını düzenlemek, sürdürmek ve sözleşmeler yoluyla uygun ödülleri ve riskleri değiştirmek için kullandıkları bir NPG aracı olarak görülebilir (Casady vd., 2019).

KÖSİ terimi daha ziyade, özel sektörün kamu hizmetleri ve altyap1 sunumunda yetki, sorumluluk, kaynaklar, riskler ve faydaları kamu ile ortaklaşa paylaşmaya yönelik bir düzenleme olarak anlaşılmaktadır (Hodge ve Greve, 2007; Grimsey ve Lewis, 2004). KÖSİ'ler, özellikle hüküm süren neoliberal gündemler ve Batı'daki refah devletinin çöküşü ile birlikte birçok yerel hükümet tarafından kabul edilmiştir (Bloomfield, 2006; Sclar, 2015).

\section{NEOLIBBERALIZM VE KÜRESELLEŞMENIN YEREL YÖNETIŞSiM ÜZERINE ETKISII}

Yönetişim, politik bir karar alma sürecini ve ayrıca belirli bir kurumsal bağlamdaki aktörleri, sosyal grupları ve kurumları parçalı, belirsiz ortamlarda tartış1 $1 \mathrm{~m} ı s ̧$ ve toplu olarak tanımlanmış uygun hedeflere ulaşmak için koordine etme sürecidir (Taşan Kok, 2010). Yönetişim sadece kamu ve özel sektör oyuncuları arasındaki sürekli değişim ile tanımlanamaz. Çünkü politikaların çoğu uygulama sürecinde nihai şeklini alır (Pierre, 1999). Bu nedenle, uygulama süreci, mülkiyete dayalı kalkınmanın yerel hükümetin politika gündemini oluşturduğu kentsel sistemlerde ve yönetişim formlarının başarısında önemli bir adımdır. Başarılı uygulama, makro düzeyde kurumsal bağlam ile bireysel aktörler arasındaki mikro kurumsal bağlar arasındaki uyuma bağlı olacaktır (Taşan Kok, 2010).

Kurumsal yönetim ve değer sistemlerindeki (normlar, inançlar, uygulamalar vb.) farklılıklar, farklı kentsel politika tercihleri ve sonuçları ürettiği için çeşitli yönetişim modelleri vardır (Pierre, 1999: 375). Bu, özel sektör aktörlerine ve sivil toplumun bir kısmına, ulusal veya yerel yönetim tarafindan sağlanan hizmetlerin yönetiminde daha büyük bir rol vermektedir. Hiyerarşik ve yukarıdan aşağı ilişkilerle, kuralların nispeten bürokratik bir şekilde konduğu devlet temelli düzenlemeler karşılaştıııldığında, paydaşlar arasında güvenin ikincisinde yüksek olduğu gözlemlenmektedir (Swyngedouw, 2005).

Örgüt olarak yönetimler kurumsallaşmış yapılara sahiptir. Buna karşı1ık, yönetişim bir çalışma sürecine ve farklı kuruluşlar arasındaki ortak çabalara daha 
çok atıfta bulunur. Bu kuruluşlar arasındaki karmaşık ilişkiler nedeniyle, yönetişim kamu alanını yönlendirmek için daha az resmi bir yaklaşımdır. Yönetim otoritesi birbirine bağımlılığa dayalı daha dinamik bir etkileşime girmiştir (Edelenbos ve Teisman, 2008: 614).

Yerel yönetişim, bölgeye yönelik rasyonel olarak planlanmış ve koordine edilmiş bir gelişmeye dayanmaktadır. Buradaki "yönetişim" terimi hükümet, toplum ve piyasa arasındaki yeni etkileşim modelini belirlemek için kullanılmaktadır (Santos Junior, 2001). Yönetişim, içinde yaşadığı iktidar koalisyonunu oluşturan belirli bir sınıf ittifakı üzerine kurulu bir idari duruşu simgelemektedir (Santos Junior, 2017). Hükümet, piyasa ve toplum arasındaki ilişki biçimi yansitan yerel yönetişim, kişisel olmayan ve hükümetin bütünlüğünü elinde tutan demokratik mekanizmalara işaret etmektedir.

Girişimci yönetişim biçimlerine geçiş, kamu hizmetleri tedariğinde değişim; seçilen görevleri daha üst düzey yönetişime devretmek için yönetişimin yükseltilmesi, yeni sosyal aktörleri yönetim alanına dahil etmek için yönetişimin yerel uygulamalara ve düzenlemelere indirgenmesi anlamlarına gelmektedir (Swyngedouw, 2005).

\section{A. Neoliberalizmin Yerel Yönetişim Üzerine Etkisi}

Neoliberalizmin yükselişi ile yerel girişimcilik ile karakterize edilen yeni bir yerel yönetişim düzeninin ortaya çıkışı arasında doğrudan bir ilişki vardır (Santos Junior, 2017). 1980'lerden sonra neoliberalleşme süreci içinde yeni bir küresel düzenin ortaya çıkması, Fordist rejim, Keynesyen refah devletinin ortadan kaldırılması ve Bretton Woods sisteminin parçalanmasıyla aynı zamana denk gelmiştir (MacLeod, 2002). Bununla birlikte, 1990'larda sınırsız bir kentleşme hızı, kentin kentsel gelişim ve büyümedeki rolünde politik ve ekonomik değişimlere neden olmuştur. Bir neoliberal projenin çoklu coğrafi ölçeklerde izlenmesi ve siyasi uygulamaları, sosyo-uzamsal kutuplaşma ve düzensiz kentsel gelişim ile sonuçlanan yaygın çelişkiler yaratmıştır. Sonuç olarak, şehirler "coğrafi ve kurumsal" yeniden yapılandırma ve çoğaltma laboratuvarları olarak ortaya çıkmıştır (Smitha, 2017).

$\mathrm{Bu}$ anlamda neoliberalizmin sosyo-mekansal dönüşüm süreci olarak algılanması daha doğru olacaktır (Theodore vd., 2009: 3). Neoliberalleşme, neoliberal ilkelere dayanan serbestleştirilmiş bir piyasada sermaye birikiminin dinamikleri için uygun kurumların, düzenleyici çerçevelerin ve kentsel yapıların yıkılmasını / yaratılmasını içeren bir dinamik ile karakterizedir (Theodore vd., 2009: 3).

Neoliberalleşme süreci, merkezi hükümet tarafından yeniden dağıtıcı politikaların açıkça paradoksal olarak uygulanmasıyla ulusal bağlamda gerçekleşmektedir. Ancak, bu yeniden dağıtım politikaları, belediyelerin yönetimlerinde artan sorumluluklar almaya başladıkları, belediye ve sosyal politikaların ademi merkeziyetçiliği bağlamında geliştirilmiştir. Neoliberal politikalar, özellikle metropol bölgelerde, yerel düzeyde güçlü bir şekilde ortaya çıkmaktadır. Bu ulusal ve yerel politikalar dizisinin benimsenmesinin sonucu, 
aslında neoliberal Keynesçilik olarak adlandırılabilecek ulusal yönetim standardını karakterize etmektedir (Santos Junior, 2017).

Ancak neoliberalleşme sürecinin yerel düzeyde gerçekleşmesi için, şehirlerde, kendi kendine düzenlenmiş piyasaya ve özel mülkiyete dayalı olarak, araziye ve ihtiyaç duyulan kentsel donanıma erişim için tek mekanizma olarak, yeni bir yönetim modeli oluşturmak gerekmektedir. Yeni liberalleşme kavramı, daha önce kendi kendini düzenleyen piyasanın tüm faaliyetlerini kısıtlayan kurallara veya sosyal ve kültürel sözleşmelere bağlanan yaşamın yeniden üretim alanlarında metalaşmanın genişlemesini tam olarak ifade etmektedir (Theodore vd., 2009).

Neoliberal politika gündemi çerçevesinde, yerel yönetimler, girişimciliğin dolaylı tanıtımından mülkiyet öncülüğünde kentsel gelişime doğru yönelmektedir. Böylece özel ve kamu tarafları arasındaki işbirlikleri teşvik edilmektedir (Swyngedouw vd., 2002). Kamu sektörü, mekânsal müdahale yoluyla ekonomik ve sosyal yeniden yapılanma arayışı içinde büyük ölçekli projelere başlamaktadır. Genel olarak kamu sektörü tarafindan başlatılan projelerde, mahallelerin yenilenmesi, yeniden canlandırılması için büyük ölçekli kentsel dönüşüm öngörülmekte ve ayrıca daha büyük bir bölgenin sosyal koşullarını iyileştirmek için özel yatırımı çekecek bir tür yeniden yapılanma sunulmaktadır. Bu nedenle, özel sektör katılımı, özel sermaye birikimini uyarmak için teşvik edilmektedir.

$\mathrm{Bu}$ projeler yeni yönetim biçimlerinin oluşumuna, şehirdeki politik, ekonomik ve sosyal güç ilişkilerine, aynı zamanda yeni araç ve planlama süreçlerinin yükselişine bağlanmaktadır (Swyngedouw vd. 2002). Bir başka görüşe göre bu projeler sosyal adalet, katılım ve demokrasi meselelerini girişimci yönetişimin mülkiyet öncülüğünde ele almaktadır (Moulaert vd., 2007). Yani projeler, girişimci yönetişim uygulamalarını, demokrasi ve katılım konularını ve çeşitli çerçevelerdeki mülkiyete dayalı kalkınmayı vurgulamaktadır.

Neoliberalleşmenin inşası altındaki politikalarla, şehirler, yerel topluluk biçimlerinin dağılmasıyla karakterize edilen mahalle, sosyal örgütler ve daha sonra şehir nüfusunun büyük bir bölümünün ekonomik ve politik olarak dışlanması şeklinde yeni bir sosyo-mekansal parçalanma biçimi yaşanmıştır (Jessop 2002). $\mathrm{Bu}$ nedenle, istihdam olanaklarının mekansal yayılması ve "kayıt dışı sektörün" teşvik edilmesi gibi sorunlarda genel bir artışla, dolayısıyla servet ve gelirdeki eşitsizliklerin artmasına katkıda bulunarak, tüm küresel şehirlerde fark edilen kentsel yoksulluk ve fakirleşme vurgulanmaktadır. Kentsel girişimcilik ile ilgili literatür, sürmekte olan kurumsal ve yapısal kısitlamalar altındaki kentsel dezavantajlı toplulukların, dışlayıcı girişimci uygulamalar bağlamında hayatta kalmak ve gelişmek için mücadele ederken, kentin yoksul semtlerinin nasıl dezavantajlı olduğunu ortaya koyamamaktadır (Smitha, 2017).

\section{B. Küreselleşme ve Küresel Şehirler Bağlamında Yerel Yönetişim}

Araştırmalar, gelişmiş kapitalist dünyadaki şehirlerin ekonomik ve mekânsal manzarasının nasıl yeniden şekillendirildiğini göstermektedir. Bu araştırmalardaki "bilgi şehri”, "girişimci şehir", "ulus ötesi şehir", "dünya şehri”, "küresel şehir", "akıllı şehir" gibi ifadeler, küreselleşme ve yerel süreçler arasındaki dinamik arayüzünü yansıtmaktadır (Jessop ve Sum, 2000; Smitha, 
2017). Bu tabirlerle anılan kentler, dünya ekonomisine entegre bir süreçte, yönetim ve hizmet merkezleri olarak ortaya çıkmıştır. Ortaya çıkan bu kentsel formlar küresel üretim sistemleri, finans, teknoloji / telekomünikasyon, kültür, politika aracılığıyla ifade edilen çok yönlü ve daha geniş karmaşık coğrafi ölçeklerdedir (Smitha, 2017).

Şehirler, ulusal ekonomik büyümeyi teşvik etmek ve yerel gelir kapasitelerini güçlendirmek için ekonomik gelişmeye öncelik vererek, küresel ekonomiye bağlanır. Siyasi ve ekonomik yeniden yapılanma arasındaki etkileşim, yerel kamu girişimcileri için talep yaratarak hizmet sunumuyla bağlantılıdır. Dolayısıyla, böyle bir yeniden yapılanma süreci, esas olarak, sermaye birikimi için yeni üretim süreci ve "yer pazarlaması" ile ilgilidir. Küresel sermayeden etkilenen şehirler "yeni talepler" için bir site olarak ortaya çıkmıştır. Fakat bu süreç, genellikle eşitsizlik ve yoksunluk ile temsil edilmektedir (Smitha, 2017).

Yeni kentsel stratejiler, küresel ekonominin etkisi altında kentsel yönetişimin hızla dönüştürülmesi bağlamında, iç yatırımlar yoluyla yerel ekonomik kalkınmayı teşvik eden büyüme yanlısı öncelikleri önemsemekte ve mobil sermayeyi çekmek için gerekli koşulları yaratmaktadırlar. Bu yüzden, kentsel yönetimler artık refah ve hizmetlerle ilgilenmek yerine, daha ziyade, rekabet stratejilerini teşvik eden politik projeleri hayata geçirmekte ve firmaların yerel yerleşimlerini geliştirmek için yeni mobil sermaye biçimlerini çekmeye çalışmaktadırlar. Kentsel yapısalcı literatür kentsel girişimi, kenti cazip hale getirecek bir imgeleme projesi olarak tanımlamaktadır (Smitha, 2017).

Yerel ekonomik kalkınmanın artan ilgi görmesinin ana nedenlerinden biri küreselleşmedir. Küreselleşme ilk etapta paranın hareketliliğini içerir. Ulusal sınırlar daha az önemli hale geldikçe, yerel bankalar üzerindeki dış pazarların rekabet baskısı daha da artmaktadır. Bankaların risk değerlendirmeleri kredi ve risk sermayesi sağlamalarını zorlaştırmaktadır. Kamu bütçe fonlarının azaltılmasına yönelik genel eğilim, yerel finansmanda ciddi sıkıntılar yaratmış, kamu kesimi, yerel düzeyde finansman sağlama ve denetleme için genel stratejik hedefler koymakta zorlanmıştır. Merkezi hükümetten ulusal düzeydeki hükümet seviyelerine yapılan mali transferler, yerel saymanlara para akışını sağlamanın en kolay yolu gibi görünse de genellikle şartlıdır; yani yalnızca belirli amaçlar için ödenebilecekleri anlamına gelir. Fonlara erişim ve kullanımlarını rapor etmek için gerekli olan idari prosedürler zordur. Bütün bunlar yerel yönetim maliyetlerini arttırmakta ve kıt kaynakları tüketmektedir. Bununla birlikte, sadece şirketler için değil, aynı zamanda bölgeler ve şehirler için mevcut endojen potansiyelin ortaya çıkmasını destekleme ve teşvik etme kapasitesi, ilgili finansal kaynaklara büyük ölçüde bağlıdır. Finansal kaynaklar arttıkça, yerel yönetimlerin yerel altyapıya yatırım yapma isteği ve kentin yatırım cazibesi artacaktır. Bununla birlikte, asıl sorun bu hedeflere bugün nasıl ulaşılacağıdır (Kuhle, 2007).

\section{II. "GİRIŞIMCİ ŞEHIRCILIK" PROJESİ}

Geniş bir teorik literatür üzerine inşa edilen ampirik çalışmalar, yerel yönetimlerin ve bunların gelişim politikalarının ABD, Avrupa ve Güneydoğu Asya'da yönetimden "girişimci" kentsel yönetim biçimlerine geçişi nasıl 
kapsadığını açıkça göstermektedir (Smitha, 2017). "Refah"1n yeniden yapılandırıldığı çeşitli kurumsal-yapısal deney ve stratejilerin desteklendiği, hizmet sunumunun KÖSİ şeklinde yeniden tasarlandığı gözlenmektedir. Devletin kentsel gelişimden çekilmesi, kentsel planlama ve politikadaki kurumsal etki, e-yönetişim önlemlerinin alınması neoliberal uygulamaların içeriğe özgü spesifik biçimini ortaya koymuştur.

Girişimci şehirciliğin amacı, kentsel girişimleri ve yerel bağlamda üretilen kurumsal çerçeveleri, politika rejimlerini, düzenleyici uygulamaların ve geniş bir coğrafi ölçek yelpazesindeki yerel mücadelelerin etkileşimi ile tanımlanan projeleri bağlamsallaştırmaktır. Ulusal ve yerel siyasi ekonomik yeniden yapılandırma, "girişimci" yeni yönetişim biçimleri yarattığına dair çeşitli yönetimsel kanıtlar sunmaktadır. Çağdaş yerel süreçler, neoliberal bir projeyi sürdürmek ve birleştirmek için (Jessop, 2002);

- Şehirlerin ekonomik büyüme, yenilikçilik ve rekabetin motorları olarak nitelendirmekte,

- Yeni bir işe girmeye teşvik edilmesini, sosyal dışlanma ve çatışmalarla mücadelede piyasa temelli çözümler sunulmasını,

- Sübvansiyon ve dayanışma ilkelerinin teşvik edilmesini,

- Altyapının iyileştirilmesi ve yerel girişimcilik rekabetçiliğinin arttırılması için ittifaklar üzerinde durulmasını,

- Kararların, hizmet, eşitlik ve sosyal refahtan ziyade maliyet-fayda kriterinden kaynaklanmasını vurgulamaktadır.

Dolayısıyla neoliberal şehir, ekonomik rekabet ve yeniliğe ulaşmak için önce "girişimci" olarak kavramlaştırılmıştır. Neoliberal projenin güvenliğini sağlamak için, kentsel yönetim kademeli olarak "kentsel girişimciliğe" geçiş yaparak farklı mekansal ölçeklerde farklı biçimlerde ortaya çıkmıştır. Harvey (1989) "girişimciliği" kategorik olarak daha geniş bir "sermaye mantığı" çerçevesine yerleştirir. "Kentsel Girişimcilik"in üç ilkesi bulunmaktadır (Smitha, 2017);

- İşs seçkinlerinden yüksek düzeyde etkilenmiş yerel yönetimler,

- "Şehrin imajını" geliştirmek için uygulanan spekülatif "mega projeler",

- "Bölge" yerine "yerel" politik ekonomi tarafından yönlendirilme.

Kentin büyüme makineleri olarak adlandırılan bu oluşumlar, kentin kalkınma hedeflerini tanımlamak ve uygulamak için birlikte çalışan devletin yerel şubelerinin ve yerel sermaye paylarının birleşimini temsil eder (Rogerson ve Boyle, 2000: 135). Koalisyon üyeleri şehirden şehre değişebilir, yerel olarak bağlı iş elitleri, yerel devlet memurları ve bazen işçi sendikaları ve diğer aktörleri içerebilir.

Yerel yönetişimde, KÖSİ yoluyla büyüme yanlısı politikaları finanse etme ve düzenleme rolünü arttırma gibi örgütsel kaymalar yaşanmaktadır. Avrupa ve ABD'de "girişimci şehircilik" üzerine yapılan birçok ampirik çalışma, kentsel gelişim projelerinin gerçekleştirilmesinde ve düzenlenmesinde devletin değişen siyasi coğrafyalarını belirlemiştir (MacLeod, 2002). Bu açık politika değiş̧iklikleri ve yerel düzeydeki yeni örgütsel kaymalar, kentsel sorunlara olan tepkilerin göstergesidir. Şehri "rekabetçi ve yenilikçi”" olarak konumlandırmak için finans, 
bilgi sistemleri, yerel vergi tabanının genişletilmesi, yatırımların çekilmesi konularında komut ve kontrol işlevlerinin edinilmesine destek olmak amacıyla çeşitli açık kurumsal yapılar ve stratejiler geliştirilmiştir. Bu tür girişimcilik faaliyetleri, bilgi teknolojileri gibi sanal ekonomiyi destekleyen sibernetik altyapının kurulması, ölçek ekonomilerinin desteklenmesi, yeni işgücü piyasası ilişki biçimleri yaratma ve küçük firmaların büyümesi şeklinde teşvik edilmiştir. Böylece kentsel hiyerarşi yeniden tanımlanmıştır. Girişimimci bir şehirle, restore edilmiş su kenarları, spor alanları veya tüketim bölgeleri gibi şehirlerde mega geliştirme projeleri, cazip kentsel ekonomiler için bir derinlik olarak turizm gibi "kentsel imaj" yaratma yönünde düzenlenmiş projelerin üretimine yoğunlaşılmıştır (Jessop ve Sum 2000).

Kentsel girişimcilik kapsamının, bir dizi aktör, fikri mülkiyet rejimi, üretim ve yönetim gibi yoğun kurumsal ve sosyal ağlar biçiminde çeşitli mekansal ölçeklerde genişlediği gözlemlenmektedir. Böylece yerel büyümenin teşviki veya yerel alanların pazarlanması sağlanabilecektir. Örneğin, uluslararası rekabet edebilirliği sağlamak için pek çok kentte, KÖSİ ile başlatılan mega projelere rastlanmaktadır (Gillen, 2009). New York, Londra ve Tokyo gibi şehirler, üretim, finans ve yönetim sistemlerindeki küresel rolleriyle değişen bir ekonomik karakter sergilemiştir. Benzer şekilde Hong Kong, Singapur, Kuala Lumpur ve Pekin'de benzer projelerle giderek uluslararasılaşan finans ve üretici hizmet sektörleri için gelişen bir merkez olarak ortaya çıkmıştır (Jessop ve Sum 2000; Shin 2009). Sonuçlar "rekabet edebilirliğin" ve "inovasyonun" modern hayalleri ile bağlantılıdır. Zheng (2011) tarafından yapılan araştırmada, gökdelenler ve yaratıcı endüstriyel kümeler ile Şangay şehrinin bir dünya kenti olarak dönüşümü vurgulanmıştır. Böylece yerel politikalar, bir kent imajının nasıl görünmesi ve çalışması gerektiğiyle ilgili uluslararası standartlara uyacak şekilde yeniden düzenlenmiştir. Yerel yönetimler çekicilik ve "inovasyon” gibi "girişimciliğin" ilkelerini, imaj oluşturma stratejilerini ve "küresel" standartları teşvik etmek için yerel politikalara dahil etme yollarını aramışlardır. Bu nedenle kentsel yönetişim, "sermaye"yi çekmeye ve kazançlı bir iş ortamını desteklemeye yönelmiştir. Kentlerin bu imaj oluşturma alıştırmalarının farklı şekillerde gerçekleştirilmesinin yanı sıra, odaklanma da bu değişikliklerin kurumlar, kentsel çevre üzerindeki etkilerine yönelik olmalıdır (Jessop ve Sum 2000; MacLeod 2002). Yani, "kentsel girişimcilik" projesinin açıkça yeni sosyo-mekansal dişlama biçimleri üretmesi üzerine çalışılmalıdır.

\section{YEREL YÖNETİŞIM VE KÖSİ}

KÖSİller birçok ülkede kentsel planlamada yaygın olarak kullanılmaktadır. Örneğin, yerel ekonomik gelişme, kentsel kıyı gelişimi ve diğer kentsel dönüşümler ayrıca temiz su ve sıhhi tesisat sistemlerinin sağlanması, altyapı inşası, okul tesislerinin dönüştürülmesi, binaların restore edilmesi, mahalle ticaret merkezlerinin canlandırılması gibi çok çeşitli görevleri üstlenmektedirler (McCarthy, 2007; Sagalyn, 2007: 7). 


\section{A. Kavramsal Olarak KÖSi}

Uygulamada çok sayıda KÖSİ türü vardır. Yapılacak bir tanımın bunların hepsini içermesi ve planlama ile ilgili görevleri çözmek için en yaygın kullanılan türlerin özelliklerini tam olarak tanımlaması olası değildir. Kapsamlı bir tanım olarak, KÖSİ'ler tarafların ortak bir hedefe ulaşmak için işbirliğini kabul eden bağımsız kuruluşlardan oluşan, amaca ulaşmak için yeni organizasyon yapıları veya süreçlerin oluşturulduğu, ortak bir programla ilgili bilgilerin, risklerin ve faydaların paylaşıldığı ortak çalışma ilişkileridir (Lamie ve Ball, 2010: 111).

KÖSİ, kamu hizmetlerin sağlanmasında, kamu ile özel sektör arasında uzun vadeli bir sözleşme olarak tanımlanabilir. KÖSİ düzenlemeleri, kalifiye eleman ve başlaması için önemli bir nakit harcaması gerektiren büyük projeler için kullanışlıdır. Ayrıca, devletin kamuya hizmet veren herhangi bir hizmete yasal olarak sahip olmasını gerektiren ülkelerde de kullanışlıdır. KÖSİ programının hizmet sağlanmasında alternatif olarak kullanımının bir çözüm olması ve bu zorlukların üstesinden gelmesi beklenmektedir. Genel olarak, KÖSI'yi tanımlayan kavramlar Tablo 1'de açıklanmaktadır (Putri ve Wirahadikusumah, 2019).

Tablo 1. KÖSİ Kavramı

\begin{tabular}{|l|l|}
\hline \multicolumn{2}{|c|}{ KÖSİ Kavramı } \\
\hline İşbirliği & $\begin{array}{l}\text { Hükümet, özel sektör ve toplum arasında karşılıklı } \\
\text { yarar sağlayan işbirliği }\end{array}$ \\
\hline Varlık & Kamu tarafindan sahip olunan \\
\hline Risk & Paylaşımlı \\
\hline Hükümetin Rolü & $\begin{array}{l}\text { Kolaylaştırıcı / özel sektör tarafından sağlanan } \\
\text { hizmetler için ödeme }\end{array}$ \\
\hline
\end{tabular}

Kaynak: Putri ve Wirahadikusumah, 2019: 2.

KÖSİ'lere, kamu sektörünün yükünün azalması, dış kaynak kullanımı ve dolayısıyla üretim sürecinde potansiyel verimlilik kazanımlarının yanı sıra bir dereceye kadar özelleştirmeyi ima ettikleri için neo-liberal bir bakış açısından bakmak daha yararlıdır (Siemiatycki, 2007: 390). Neo-liberal rejimler altında çoğu ülke yerel hizmet üretiminde sivil toplum kuruluşları ve özel aktörlerle dış kaynak kullanarak gerçekleştirmiştir. Şehrin stratejik ortaklıkları, hizmet sunumuna katılan tüm kuruluşları planlama sürecine katkıda bulunmaya teşvik edilerek, yerel bir otorite alanında kamu hizmeti sunumu yeniden birleştirmeye çalışılmaktadır. Ortaklıklar, kurucu organların yargı bütünlügünü kabul ederken sektörler arası işbirliğini kurumsallaştırmaktadır. Tüm ortakların kendi planlarını topluluk planına uyması ve belirli hedeflere doğru çalışması beklenir. Bunlar, merkezi ve yerel yönetim ile diğer yerel kurumlar arasındaki yerel alan anlaşmalarında resmileştirilmiştir (Davies, 2009: 83; Lamie ve Ball, 2010).

Ayrıca, KÖSİler risk sermayesi için karlı yatırım firsatları ve risk paylaşımı sağlar. Bir yönetim reformu olarak KÖSİ, "büyük ölçüde pazarın disipline ederek devletin işleyiş şeklini değiştirecek yenilikçi bir araç" olarak tanıtılmaktadır (Linder, 1999: 42). KÖSİ'ler yerel imaj inşasına ve kentin rekabetçiliğine yardımcı olan mega projelerin uygulanmasını kolaylaştırmaktadır. 
Genellikle sağlanan altyapıdan özel kazançlar olacaktır; örneğin, yol kapasitesinin artmasından kaynaklanan zaman tasarrufu gibi (Hodge vd., 2010).

Bir yandan, KÖSİ'lerin kamu hizmeti sunumunda özel sektörün rolünü artırarak daha fazla verimlilik sağlamaları beklenmektedir. Hodge ve Greve (2007), birçok başarılı KÖSİ projesine örnek vermişlerdir. Öte yandan, Asya'daki gelişmekte olan şehirlerde yaygın olarak gözlenen bazı istenmeyen sonuçlar (maliyet aşımları, işbirliği, zayıf fizibilite çalışmaları ve yolsuzluk) hakkında endişeler dile getirilmiştir (ESCAP, 2012; Gediz Oral, 2015; Gediz Oral ve Arpazlı Fazlılar, 2015). Özellikle dünya genelinde mega proje KÖSİ'leri arasında bir dizi KÖSİ 'başarısızlığı' kaydedilmiştir. Bu başarısızlıklar iptal edilmiş tavizler, durdurulmuş projeler, projelerin millileştirilmesi ve askıya alınmış sözleşmelerdir (Soomro ve Zhang, 2013). KÖSİ'ler anlayışlarında ideal görünmekle birlikte, yanlış uygulamalara kolayca yenilebilirler.

\section{B. Yerel Finansmanda KÖSİ Avantajları}

Yerel otoriteler entegre finansal tedarik zincirlerine sahip olmaktan hala çok uzaktır. Bunun nedenleri arasında şunlar bulunmaktadır (Kuhle, 2007):

- Yerel otoriteler, yatırımcilar ve aracilar arasındaki mevcut finansman olanakları hakkındaki bilgi eksikliği,

- Yatırım yapmak için yetersizlik,

- Yerel yetkililerin yatırımcı ve girişimci gereksinimlerini farkında olmamaları,

- Yerel yönetimler içindeki zayıf yönetim ve finansal sistemler,

- Yerel yönetimlerin bankaların ihtiyaç duydukları teminattan yoksunlukları. Dolayısıyla, finansmanda çeşitli boşluklar vardır. Kamu kesimi, özel sektör yatırımcıları için riskleri azaltmak (örneğin, garantiler yoluyla) ve bazı finansman türlerinin arzı için kamu fonlarının kullanılması gibi önemli bir eylem alanına sahiptir.

KÖSİ'ler finansman programlarını optimize etmek için yerel otoriteleri, finans sektörünü ve kar amacı gütmeyen kuruluşları bir araya getirmenin, yerel olarak girişimciliği teşvik etmenin en etkili yollarından biridir. KÖSİ'ler, küçük işletmeler tarafından kolayca erişilebilen ve ihtiyaçlarına göre uyarlanmış destek mekanizmaları da sağlamaktadır. Kamu sektörü için özel sektörle işbirliği böylece yüksek kaldıraç oranına ulaşmaktadır. Ayrıca, sınırlı kamu fonlarının daha verimli kullanılmasına imkan sağlanmaktadır. Kamu sektörü, mikro kredi kurumları tarafindan fon yaratma ve kredi vermeyi kolaylaştırmak için yasal çerçevenin iyileştirilmesi yoluyla katkıda bulunmaktadır. Bununla birlikte, KÖSİ, kamu sektöründe güçlü yerel liderlik gerektiren bir yönetim aracıdır (Kuhle, 2007).

Yerel destekçilerin ve çeşitli büyüklükteki yatırımcıların varlı̆̆ını somutlaştırmak, özel finans dahil, yerel ekonominin finansal tanıtımında yerel kamu politikalarının önemini göstermektedir. Yerel liderlerin bunu gerçekleştirememesi yalnızca hedeflenen kamu yatırımlarının kaldıraç etkisinin optimize edilememesi anlamına gelmemekte, aynı zamanda siradan kamu hizmetleri optimal ekonomik ve sosyal dağılımdan uzaklaşmaktadır. Özel finansmandan yararlanmak için kaynaklar hem kamu hem de özel finansmanı 
kullanmadan destekçilere transfer edilirse, bu yerel pazarları canlandırmamaktadır. Unutulmamalıdır ki bu pazarlar sürdürülebilir yerel ekonomik kalkınmanın tek garantisi olmaya devam etmektedir (Kuhle, 2007).

Yerel ekonomik gelişmeyle karşı karşıya olan finans sorunları büyük ölçüde yapısaldır ve kamu sektörünü kapsayan uzun vadeli çözümler gerektirir. Bununla birlikte, yerel yönetimlerin rolü, her şeyden önce, bankaları daha fazla açıklık ve iletişimi kullanmaya davet etmek için, kolaylaştırıcı ve katalizör olarak görülmelidir. Kamu sektörünün finansman sağlama için genel stratejik hedefleri koyması ve denetimin bu seviyede olması gerektiği kabul edilirken, finansal araçların yönetiminin ticari olarak yapılmasının önemi vurgulanmaktadır (Kuhle, 2007).

Yerel KÖSİ'lerde, yönetilen fonlar kredileri ve kredi garantilerini sağlamada etkili bir yoldur. Çünkü bankaları yerel borçlularına borç vermek için kullanabilirler. Kamu sektörü hem kredi hem de garanti bileşenlerine sahip olabilir veya teminatsız olarak mikro krediler sağlanabilir. Bununla birlikte, özellikle yerel makamlar, riskin kamu ve özel sektör arasında dengeli bir şekilde dağıtılmasına dikkat etmelidir (Kuhle, 2007).

\section{YEREL KÖSİ PROJELERININ ZORLUKLARI}

Büyük ölçekli yerel projelerin KÖSİ şeklinde uygulanmasının bir takım zorlukları bulunmaktadır. Bu kısım, uygulamanın zorluklarını belirlemek, tartışmak ve neoliberal çağda çok oyunculu yönetişimin karmaşıklığına ışık tutmak için bir çerçeve tanımlamaktadır. İyi işleyen bir sistem, zorlukları aynı anda karşılayabilen ve ortaya çıkan ihtiyaçlara cevap verebilecek kurumsal yenilikler üretebilir.

Büyük ölçekli projelerin amaçları ve araçları, sosyal yönelimli kamu rejenerasyon programlarından, özel sektör sermaye birikimine yönelik programlara kadar değişmektedir. Bu ikileme bağlı olarak, büyük ölçekli projeler literatürde; az sayıda yerel sosyal faydaya sahip, yüksek kârlı sektörlere sponsorluk yapması, kapsamlı ve bütünleştirici planlama kavramından yoksun olması, halkın maliyetler ve faydalar hakkında yanlış bilgilendirilmesi, hesap verilebilirliği sağlayacak ve hedeflere nasıl ulaşılacağını ölçen mekanizmaların bulunmaması ile ciddi biçimde eleştirilmektedir (Flyvbjerg, 2005).

Moulaert vd. (2007) eleştirilerini daha fazla parçalanma, eşitsizlik ve sosyo-ekonomik dengesizliğe doğru gelişen yeni kentsel politika çerçevesinde ele almıştır. Geniş çaplı projelerin sosyal sonuçlarının sosyal inovasyon çerçevesinde tartışılmasını önermektedirler. $\mathrm{Bu}$ mahalle ve toplum yönetimi arasındaki ilişkilerde inovasyon yoluyla insan ihtiyaçlarının karşılanması anlamına gelmektedir. Açıkçası, özel sektör gündeminde olmamasına rağmen, yetersiz hizmetlerin sunulması için sosyal inovasyona yönelik vurgu değişikliğine olan ihtiyaç bu projelerde artmaktadır (Moulaert vd., 2007).

Bu sorunlara rağmen, stratejik kentsel lokasyonlarda proje öncülüğünde gelişme, yeni kentsel politikayı özel sektörle uyum içinde uygulamak ve büyükşehir ekonomilerinin rekabet gücünü yeniden güçlendirmek için şehir yönetimleri arasında popüler bir stratejiye sahiptir. Ancak yeni kentsel politika, 
paydaşlar için birçok zorluk yaratmaktadır. Belki de en önemli makro düzeydeki zorluk, bu yeni yönetim biçimlerinde kuralların ve normların çok net bir şekilde tanımlanmaması veya anlaşılmamasıdır. Dahası, kentsel yönetimler için en büyük zorluk, büyük ölçekli projelerde demokrasi pratiğini ve sosyal adaleti oluşturmak ve sürdürmek, mekansal müdahalelerle demokrasiyi ve dışlanmış sosyal grupları güçlendiren adil ekonomik ve sosyal koşulları yaratmaktır (Swyngedouw, 2005). Tasarım, geliştirme ve uygulama süreçleri bir kurumsal sistemden diğerine değişen zorluklar yaratmaktadir.

Gelişmekte olan ülkeler incelendiğinde, yerel KÖSI'lerin faaliyet gösterdiği politik ve kurumsal ortamların kritik hale geldiğini söyleyebiliriz. Çünkü bu ülkelerde yerel demokrasiden ve işleyen bir piyasa ekonomisinin varlığından söz edilemez. Bu gibi durumlarda, KÖSİ sözleşmelerinin tasarlandığı, işletildiği siyasi ve kurumsal çerçevelerin daha dikkatli bir şekilde incelenmesi gerekmektedir. Gelişmekte olan dünyada KÖSİ'leri inceleyen Miraftab (2004), eşit olmayan oyun alanını, devlet ile özel sektör arasındaki eşitsiz güç dağılımını KÖSİ'leri zedeleyen önemli bir faktör olarak tanımlamıştır.

KÖSİllerin lehine en sık konuşulan tartışma, rekabetçi tedarik süreçleri, kamu ve özel sektörün gelişmiş becerileri, yönetim, teknoloji ve risk tahsisi avantajlarını getirerek kamu altyapısının sağlanmasıdır (Osei-Kyei ve Chan, 2015). Geleneksel kamu altyap1 ve hizmet sunumunun, özellikle zaman yönetimi ve sermaye maliyetleri bakımından verimsizliği ve yetersizliği, KÖSİ'lerin kabul edilmesini daha da arttırmıştır (Flyvbjerg vd., 2002). Kısacası, kaynak sıkıntısı çeken yerel yönetimler, KÖSİ'yi kamu hizmeti sunumu için yeni bir araçsal ve normatif mekanizma haline getirerek, özel sektörün uzmanlığı ve güçlü yönlerinden yararlanarak maliyet tasarrufu yapmayı, riskleri paylaşmayı ve kamu hizmeti kalitesini yükseltmeyi hedeflemektedirler. Bununla birlikte, KÖSİ'lerin faydaları garanti edilememektedir.

\section{A. Seçkinlerin Hakimiyeti ve Demokratik Katılımın Azalması}

Artan girişimcilik döneminden sonra, mülkiyet hakları rejimlerinin dualistik doğası daha belirgin hale gelmiştir: Bir yandan, kentsel arazi ve emlak piyasaları, üretken amaçlar için arazi kiralarının transferine (ticari mülk geliştirme) bağlıyken, öte yandan, yönetişim ilişkileri farklı sosyo-ekonomik mantıklara sahip olan (hanehalkları için) amaçları desteklemiştir. Bu yapıda, yönetişimin farklı biçimleri daha bağımlı hale gelmiş ve çeşitli aktörler arasında daha fazla etkileşim gerçekleşmiştir. Yeni yönetim biçimlerinin koşulları ve sonuçları, daha az demokratik ve elit ağırlıklı bir kent politikası oluşumuna sebep olduğundan büyük ölçüde eleştirilmiştir. Ekonomik, sosyo-kültürel veya politik elitlerin koalisyonları, devlet dişı yönetim sistemlerinin güç koreografisini yönlendirmiştir (Swyngedouw vd., 2002). Zamanla kent politikasını şekillendiren profesyonel ve politik seçkinler tarafindan yönlendirilen bu ağlar, kentsel gelişimdeki iş seçkinleri odaklı ağlara dönüşerek özel süreçlere yol açmaktadır. KÖSİ'ler normatif standartlara değinmediğinden, demokratik katılım için sorular ortaya koymaktadır (Taşan Kok, 2010). 
KÖSİ'lerle özel yatırımcılara tercihli muamele uygulanmaktadır. Ekonomik durumları iyi olanların neo-liberal kent politikalarının sunduğu malların karş1lığını ödemeye gücü yetecektir. Buna karşılık, bir programın başarısı, bir pazardaki ürünleri için ödeme yapmaya istekli olarak adlandırılan "gönüllülük" ile ölçüldüğünde, yoksul insanlara iyi hizmet sunulamayacaktır. Ayrıca sürdürülebilir kent alanları, istikrarlı iklim, temiz doğal çevre tercihleri, ancak insanların bu tür sonuçlara sahip politikalara ödeme yapmaya istekli olmaları halinde ortaya çıkabilecektir. Yani daha fazla özel sektör finansmanıyla kentsel gelişimin yönetimi, politik alanın daralması anlamına gelmektedir. Özel operatörler ve yatırımcılar politik eleştiriye açık değildir. $\mathrm{Bu}$ nedenle vatandaşların temel ihtiyaçlar, dış etkiler ve şehir çapındaki sonuçları göz önünde bulundurmaları için bask1 yapmaları daha zordur (Sager, 2011: 180).

Yerel KÖSI'ler, küreselleşmenin ortasında ekonomik milliyetçiliğe ilgi çekici bir bakış açısı sunmaktadır. Ekonominin liberalleşmesi ve küreselleşme stratejilerine rağmen, sivil toplum ve medya ulusal pazardaki görünür yabanc1 sermayenin artan varlığından giderek daha fazla rahatsız olabilir (Lee, 2012). Yabancı yatırımcıları içeren yerel KÖSİ'lerin yükselen trendi ile KÖSİ'lerin detayları halkın dikkatini çektikten sonra halkın kabulünü sağlamak kolay olmayabilir.

\section{B. Küresel Finansman, Metalaşma ve Spekülatif Piyasa}

Küresel finans sektörünün dinamikleri, yeni yönetişim modlarının temelini oluşturan, kentsel yönetişimdeki girişimcilik değişiminde çok önemli hale gelmiştir. Artan sermaye hareketliliği, mali kuralsızlaştırma bu karmaşık ilişkiler ağ yoluyla ifade edilmiş, yönetilmiş ve birleştirilmiştir. Finansal düzenlemeler, mülkiyete dayalı kentsel gelişimde etkili bir şekilde artan miktarda portföy yatırımı ve borsa işlemleriyle kentlere daha küresel finansal faaliyetler getirmektedir. Mülkiyet piyasasındaki uluslararası sermayenin artan payı, finansal düzenlemelerin başarısına bağlıdır. Yüksek derecede finansal kuralsızlaştırma, kentsel emlak piyasasını metalaşmaya açmakta ve uluslararası sermayenin nüfuz etmesini kolaylaştırmaktadır. Öte yandan, artan uluslararası sermaye miktarı ve artan oyuncu sayıları mülk piyasasını daha da karmaşık hale getirmektedir. $\mathrm{Bu}$ değişikliklerin zaman içindeki sonucu finanse edilen, geliştirilen büyük ölçekli projelerin uluslararası şirketler veya ortaklıklar tarafindan yönetilmesidir. Küresel sermaye hareketlerinin artan etkisiyle, kentsel gelişim finansal piyasalardaki dalgalanmalara karşı daha duyarlı hale gelmiştir (Taşan-Kok, 2010).

Düzenleyici kontrolün kısıtlamadığı yeni faaliyetlere yatırım yapan finansal kuruluşlar, kentsel gelişimdeki spekülasyonları arttırmıştır. Küresel sermaye piyasasının, kentsel gelişime katılımı, büyük ölçekli kentsel dönüşümün başarısında önemli bir rol oynamaktadır. Bu projelerin uzun vadeli sonuçları belirsiz olsa da özel yatırım sermayesini dahil etmek, planların uygulanmasında kentsel yönetimler için önemli bir başarı faktörü gibi görünmektedir. Kamu sektörü, daha fazla yatırım sermayesi çekmede ve bazı siteleri bu temelde canlandırmada şehir pazarlaması için büyük yatırımlar öngörmektedir. Yerel emlak yatırımcılarının ilgisi, bu tür kentsel dönüşümün başarısı için bir avantaj olmuştur. 
Bununla birlikte, küresel sermayeye olan bağımlılık, emlak piyasası krizini küresel ekonominin yavaşlamasıyla yoğunlaştırdığı için projeleri tehlikeye atmaktadır. Bununla birlikte, yerel ve küresel pazarların iç içe geçtiği ve yerel pazarla ilgisi olmayan (kiracilar, perakendeciler, vb.) uluslararası yatırım sermayesinin mevcudiyetinin büyük ölçekli projelerin başarısı için çok önemli olmayacağına dair görüşler de mevcuttur (Taşan Kok, 2010).

Büyük ölçekli projeler için yapılan uzun vadeli KÖSİ sözleşmeleri, özel sektörün taşımayı istemediği, öngörülemeyen ve kontrol edilemeyen durumlarla ilgili yüksek risklere sahip olma eğilimindedir. Bu nedenle, özel sektörü çekmek için yerel yönetimler genellikle riskin orantısız bir payını üzerlerine almaktadırlar. Ayrıca, özel sektör, ulusal ekonomik koşullara kıyasla yerel ekonomik koşullardan ve oynaklık olasılığından daha az emin olabilir. Yerel yönetimler, belirgin talep eksikliği veya talebin belirsizlik göstermesi durumunda, özel şirketlere daha fazla teşvik vermek zorunda kalabilirler. Küresel finansal piyasaların genişlemesinden yararlanarak sadece büyük şehirler ve büyük projeler sonuçlanabilir. Dolayısıyla KÖSİ kamu altyapı gelişimi için riskleri artırabilir (Bel vd., 2013; Palcic ve Reeves, 2011).

\section{C. Çok Oyunculuğun Doğası ve Zorlukları}

Planlamacılar, KÖSİ'lerle kamu hedeflerinden çok özel sektör çıkarlarına kayma yaşanabileceğinden endişe duymaktadır. Özellikle, büyük projeler, yüksek kullanıcı ücretleri gerektirebilir, bu durum gruplar ve nesiller arasındaki eşitliği azaltabilir (Miraftab, 2004). KÖSİ'lerle denetim hakları ve şeffaflık kısıtlanarak, kamu hesap verilebilirliği zayıflatılarak ve vatandaşların katılımı engellenerek demokratik sorunlar ortaya çıkabilir (Siemiatycki, 2007; 2010). Davies (2007), ulusal hükümetlerce yürütülen yeni kamu yönetiminin, demokratikleşme umutlarını aşındırdığını öne sürmektedir. Potansiyel rakiplerin gizli tutulması ve arazi sahiplerinin toprağın fiyatını etkileyebilecek bilgiyi edinmesinin önlemesi gibi nedenlerle gizliliğin korunmasına ilgi duyulmaktadır. Gizliliğin ayrıca, halkın muhalefetinin gelişmesi dolayısıyla projenin gecikmesine ve hatta terk edilmesine neden olma riskini en aza indirdiği düşünülmektedir. Siemiatycki (2010)'a göre imtiyaz sözleşmelerindeki rekabet yasağı hükümleri hükümetin değişen koşullara cevap verebilmesi için esnekliği kısıtlayabilmektedir. Ayrıca, KÖÖİ'lerin ortaklık sözleşmesinin şartlarını ve koşullarını müzakere etmek ve yönetmek için gereken zamanı ve kaynakları hafife alma eğiliminde oldukları konusunda da uyarırlar bulunmaktadir (Grimshaw vd., 2002).

\section{Planlama Sistemi Zorlukları}

Planlayıcıların, dinamik kentsel gelişim gündemine tepki vermek için kurumsal yeniliklere ihtiyacı vardır. Yönetsel hükümetten girişimci yönetim sistemlerine geçiş, paydaşlar arasında sorumlulukların parçalanmasına neden olmuştur. Bu parçalanma, ortak bir vizyonun paylaşılmasını zorunlu kılmaktadır. Ancak o zaman taraflar mekansal gelişmelerde sürekliliği ve birbirine bağlılı̆̆1 sağlayabilirler. Buna rağmen, kentsel hükümet hiyerarşisinin farklı kademelerinde formüle edilmiş ve yayınlanan planları koordine etmek zor görünmektedir (örneğin imar, kalkınma, büyükşehir planları). Bazen yetkililer, karar verme yapısında bir 
sorun ortaya çıkana kadar birbirlerinin planlarından habersiz kalabilmektedir (Taşan Kok, 2010).

Stratejik bir projenin başarısı için vizyon, konsept ve tasarım unsurları çok önemlidir. Bununla birlikte, tek başına tasarım, birbiriyle çelişen çıkarları ele almak, talepleri karşılamak ve çok çeşitli paydaşlar arasındaki güç mücadelelerini çözmek için yeterli değildir. Her projenin sosyal ve ekonomik hedefleri olmasına rağmen, sosyal kazanımlar sınırlı kalabilmektedir. Büyük ölçekli projeler, daha geniş alanların fiziksel gelişimi üzerinde ve aynı zamanda çevre mahallelerin sosyal dinamikleri üzerinde büyük bir etkiye sahiptir. Gelişimin ölçeğine bağlı olarak, etkiler şehir genelinde hissedilir (Olimpiyat köyleri, evrensel Expo projeleri gibi mega projelerde olduğu gibi) (Taşan Kok, 2010).

\section{E. Kamu Kesiminin Bilgi Eksikliği}

Büyük ölçekli bir proje ağırlıklı olarak kamu yatırımına dayandığında, özel sektörün ilgisini çekmek ve sürdürmek zor görünmektedir. Daha da önemli olanı, kamu sektörünün özel sektör operasyonları hakkındaki sınırlı bilgisidir. Birçok KÖSİ'de kamu aktörü, arazi sahipliğiyle katılan pasif bir ortak olarak kalır. Diğer durumlarda, kamu aktörü bir proje başlatırsa, müteakip gelişme adımları, kamu aktörünün bilmediği mülk pazar koşullarından dolayı net olmayabilir. Açıkçası, pazarın beklentilerini bilmek, kamu sektörüne daha verimli ve etkili bir şekilde manevra yapma imkanı verecektir. Yoğun ağlar, belirsiz kurumsal düzenlemeler, hatalı tanımlanmış sorumluluklar belirsiz politik hedefler ve öncelikler, girişimci yönetişimin zayıf tanımlanmış yapısını karakterize eder (Swyngedouw, 2005).

Swyngedouw (2005), devlet, sivil toplum ve pazar arasındaki göreceli sınırların değiştiğini savunmaktadır. Devletin ötesinde yönetişim, paydaşlar için daha açık rol tanımları gerektirmektedir. Ayrıca, devlet esaslı düzenlemeler ve devletin ötesindeki yönetişim eşzamanlı olarak gerçekleşir. Birinden diğerine belirgin bir ayrım veya kayma yoktur. Farklı yönetişim biçimleri çeşitli biçimlerde ortaya çıkarılırken, bazı devlete dayalı düzenlemeler hâlihazırda yapılmakta olabilir.

Kamuda kontrolün ve örgütsel gücün merkezileşmesi (merkezi veya şehir yönetimi düzeyinde) başarılı bir girişimcilik yönetişimi için elverişlidir. Bu, kamu ve özel paydaşlar arasındaki ilişkilerin daha iyi bir şekilde düzenlenmesi, planlar için daha etkili bir uygulama süreci ve mülk piyasası dinamiklerinin kontrollü ancak etkili katılımıyla ortaya çıkmaktadır. Bununla birlikte, projeler, sosyal ve kurumsal yeniliklerle başarılı bir şekilde uygulanmış olsalar bile, seçkin projeler tarafindan yaratılan sosyal izolasyonun önlenip önlenemeyeceği belirsizdir.

\section{F. Teknik Faktörler}

Büyük projelerin istikrarlı yönetimi olasılığını, özel ortakların katkıda bulunabilecekleri yenilikçi beceri ve teknolojiyle ilgili teknik faktörler belirlemektedir. Özellikle büyük altyapı gelişimi için yapılan uzun vadeli sözleşmeler, seçilen özel ortak için uzun vadeli bir tekel üreterek pazar rekabetini ortadan kaldırmaktadır (van Ham ve Koppenjan, 2001). KÖSİ'lerde özel sektörün "tekelleşmesinin" sonucunda, hem tüketiciler hem de hükümetler için daha yüksek 
Burcu Gediz Oral \& Tuğba Arpazlı Fazlılar / Neoliberalizm ve Yerel Yönetişim Bă̆lamında Kamu Özel Sektör İşbirliklerinin Yerel Girişimcilik Üzerine Etkileri

maliyetler ve kamu ile özel sektör arasında müzakereyle sonuçlanabilecektir (Cruz ve Marques, 2013).

\section{G. Yasal ve Siyasi Faktörler}

KÖSİler için siyasi ve yasal ortamdan kaynaklanan problemler ortaya ç1kabilir. Siyasi ve yasal ortamın istikrarlı ve deneyimli bir hükümet, şeffaf ve rekabetçi bir ihale sistemi ve KÖSİ sisteminin iyi çalışması için yeterli düzenleyici ve kurumsal bir çerçeveyi içermesi gerekmektedir. Örneğin, yerel kamu sektörünün karmaşık ve teknik KÖSİ sözleşmelerinin hazırlanmasında yeterince deneyimi olmadığ 1 kabul edilmektedir (Sclar, 2015; Dannin, 2011). İki ortak arasında güçlü bir "bilgi asimetrisi" (Siemiatycki, 2013; Sclar, 2000) ve uzmanlıkta bir boşluk bulunmaktadır. Birçok durumda, yerel yönetimler özel ortakların KÖSİ düzenlemeleri altındaki stratejik hedefleri takip etmelerini izleme ve yönetme kapasitelerine sahip değildir. Kamuda şeffaflık söz konusu olduğunda, hükümetlerin, sözleşmeler hakkında doğru bilgileri açıklama konusunda aykırı davranma sorunu da vardır (Bloomfield, 2006). KÖSI'ler, maliyetleri uzun vadeye yayarken, kamu altyapısı ve hizmet sunumunda kısa vadeli faydaların elde edilmesine izin verilir (Hodge ve Greve, 2007). Aslında, KÖSİ kararları politik etkiye sahip olmayan, yalnızca teknik çözümler içeren kararlar değildir. Aksine KÖSİ'ler çok politik olabilir (Roberts, 2010). Özellikle, yerel seçmenlerin bir sonraki seçimleri dikkate alacakları göz önüne alındığında, siyasi zaman çizelgeleri “iyimserlik yanlılığı” içinde sıkışıp kalmaya, uygun değerlendirmeleri reddetmeye ve KÖSİler için beklenen geliri fazla tahmin etmeye eğilimlidir (Grimsey ve Lewis, 2004). Bu nedenle k1sa vadeli siyasi kararlar siklıkla sorumsuz uzun vadeli sözleşmeler üretmektedir. Bu bağlamda, KÖSİ'lerin politik yapısını kabul etme ve onları yeniden siyasallaştırma gereği için politika alternatifleri hakkında tartışmayı kamuya açık forumlara getirmeye gerek duyulmaktadır (Higgins ve Huque, 2014).

\section{SONUÇ}

Girişimci ve rekabetçi ortamda, yerel projelerde ve kentsel gelişimde özel sektör daha proaktif roller üstlenmektedir. Yerel yönetimler stratejik projelerdeki finansman sıkıntısı ve işbirliği avantajları nedeniyle bunu tercih etmektedir. Fakat yönetişim sistemlerinde kamu ve özel çıkarları dengelemek büyük bir zorluk gibi görünmektedir. Özel yatırımları çekemeyen gerçekçi olmayan kamu kalkınma planlarından örnekler veya pazar odaklı projeler sınırlı kamu yararına hizmet etmektedir. Yönetişim sistemlerinde, özel sektör aktörlerinin katılımının merkezi olarak düzenlenmesi ve kamu ile özel sektör çıkarları arasında parçalı yönetişim sistemine göre daha iyi bir dengeye sahip olmaktadır.

KÖSİ'ler hem gelişmiş hem de gelişmekte olan ülkelerde çeşitli kamu hizmetleri ve altyapı sağlamak için yoğun olarak kullanılmaktadır. Literatür, gelişmiş bir finansal piyasa, şeffaf düzenleyici çerçeve, ileri teknoloji ve insanların yeni formları kabul etmesini içeren birçok yaygın kritik başarı faktörüne işaret etmektedir. Ancak bunlar ülkeden ülkeye değişebilir. KÖSİler yerel düzeyde çoğunlukla sınırlı yerel mali otorite ve kaynaklar, firsatçı davranışlar nedeniyle haksız sözleşmeler yapmaya duyarlı olabilmektedir. 
KÖSİ'lerin avantaj ve dezavantajlarına dair tartışma sürmektedir. Mevzuattaki boşluklar, kamunun süreç takibini gerçekleştirecek elemandan yoksun olması, sözleşme süresi sona erdiğinde ne olacağına dair belirsizlikler ve kamuoyunun bilgi eksikliğinin KÖSİ projelerinde sorun yaratabileceği iddia edilmektedir. KÖSİ projeleri uzun süreli olduğu için gelecek nesillerin karar alma gücü etkisizleştirilmekte ve gelecek siyasi idarenin takdir yetkisi bugünden ipotek altına alınmaktadır.

\section{KAYNAKÇA}

Banerjee-Guha, S. (2010). "Introduction: Transformative Cities in the New Global Order", In S. Banerjee-Guha (Ed.), Accumulation by Dispossession: Transformative Cities in New Global Order, New Delhi: Sage Publications, 1-16.

Bel, G., Brown, T., \& Marques, R.C. (2013). "Public-Private Partnerships: Infrastructure, Transportation and Local Services", Local Government Studies, 39(3), 303-311.

Bloomfield, P. (2006). "The Challenging Business of Long Term PPPs: Reflections on Local Experience", Public Administration Review, 66(3), 400-411.

Casady, C. B., Eriksson, K., Levitt, R. E., \& Scott, W. R. (2019). "(Re)Defining Public-Private Partnerships (PPPs) in The New Public Governance (NPG) Paradigm: An İnstitutional Maturity Perspective", Public Management Review, doi:10.1080/14719037.2019.1577909, $1-23$.

Cruz, C.O., \& Marques, R.C. (2013). "Endogenous Determinants for Renegotiating Concessions: Evidence From Local Infrastructure", Local Government Studies, 39(3), 352-374.

Dannin, E. (2011). "Crumbling Infrastructure, Crumbling Democracy: Infrastructure Privatization Contracts and Their Effects on State and Local Governance", Northwestern Journal of Law \& Social Policy, 6(1), 47-105.

Davies, J. S. (2007). "The Limits of Partnership: An Exit-Action Strategy for Local Democratic Inclusion", Political Studies, 55(4), 779-800.

Davies, J. S. (2009). "The Limits of Joined-Up Government: Towards a Political Analysis", Public Administration, 87(1), 80-96.

Edelenbos, J. ve Teisman, G. R. (2008). "Public-Private Partnership: On The Edge of Project and Process Management. Insights from Dutch Practice: The Sijtwende Spatial Development Project", Environment and Planning C: Government and Policy, 26(3), 614-626.

ESCAP (2012). A New Vision for Public-Private Partnerships (PPP) in Asia-Pacific, https://www.unescap.org/speeches/new-vision-public-private-partnerships-ppp-asiapacific, (21.03.2019).

Flyvbjerg, B. (2005). "Machiavellian Megaprojects", Antipode 37, 18-22.

Flyvbjerg, B., Holm, M., \& Buhl, S. (2002). "Understanding Costs in Public Works Projects: Error or Lie?", Journal of The American Planning Association, 68(3), 279-295.

Gediz Oral, B. (2015). "Kamu Hizmet Arzında Değișim Temelinde Kamu Özel Sektör İşbirlikleri ve Yolsuzluk", Abant İzzet Baysal Üniversitesi Sosyal Bilimler Enstitüsü Dergisi, 15, 15(4), 185-225.

Gediz Oral, B., Arpazlı Fazlılar T. (2015). Enerji Güvenliğinin Değişen İçeriği Kapsamında Enerji Sektöründe Kamu Özel Sektör İşbirliği ve Kısıtlar Enerji Projelerinde Yolsuzluk. Dokuz Eylül Üniversitesi Sosyal Bilimler Enstitüsü Dergisi, 17(4), 461-492., Doi: http://dx.doi.org/10.16953/deusbed.18799.

Gillen, J. (2009). "The Co-production of Narrative an Entrepreneurial City: An Analysis of Cincinnati, Ohio in Turmoil", Series B. Human Geography, 91(2), 107-122.

Grimsey, D., \& Lewis, M. (2004). Public Private Partnerships: The Worldwide Revolution in Infrastructure Provision and Project Finance, Cheltenham: Edward Elgar.

Grimshaw, D., Vincent, S., \& Willmmott, H. (2002). "Going Privately: Partnership and Outsourcing in UK Public Services", Public Administration, 80(3), 475-502. 
Burcu Gediz Oral \& Tuğba Arpazlı Fazlılar / Neoliberalizm ve Yerel Yönetişim Bağlamında Kamu Özel Sektör Isşbirliklerinin Yerel Girişimcilik Üzerine Etkileri

Higgins, C., \& Huque, A. S. (2014). "Public Money and Mickey Mouse: Evaluating Performance and Accountability in The Hong Kong Disneyland Joint Venture Public-Private Partnership", Public Management Review, 1-21.

Hodge, G. A., Greve, C., \& Boardman, A. (2010). International Handbook on Public Private Partnerships, Cheltenham: Edward Elgar.

Hodge, G., \& Greve, C. (2007). "Public-Private Partnerships: An İnternational Performance Review", Public Administration Review, 67(3), 545-559.

Jessop, B. (2002). "Liberalism, Neoliberalism and Urban Governance: A State-Theoretical Perspective", Antipode, 34(3), 452-472.

Jessop, B., \& Sum, N. (2000). “An Entrepreneurial City in Action: Hong Kong's Emerging Strategies in and for (inter) Urban Competition”, Urban Studies, 37(12), 2290-2315.

Kuhle, H. (2007). "The Experience of Public-private Partnerships in Financing Entrepreneurship in Eastern Germany and Poland", in Sylvain Giguère (ed.), Local Innovations for Growth in Central and Eastern Europe, OECD Publishing, Paris, DOI: https://doi.org/10.1787/9789264038523-12-en, 215-226.

Lamie, J., \& Ball, R. (2010). "Evaluation of Partnership Working within a Community Planning Context", Local Government Studies, 36(1), 109-127.

Lee, Y. -I. (2012). "South Korea's Globalization in The Late Twentieth Century: An End to Economic Nationalism?", In A. P. D'Costa (Ed.), Globalization And Economic Nationalism In Asia, Oxford: Oxford University Press, 157-176.

Linder, S. H. (1999). "Coming to Terms with The Public-Private Partnership", American Behavioral Scientist, 43(1), 35-51.

MacLeod, G. (2002). "From Urban Entrepreneurialism to a 'Revanchist City' on the Spatial İnjustices of Glasgow's Renaissance", Antipode, 34(3), 602-624.

McCarthy, J. (2007). Partnership, Collaborative Planning and Urban Regeneration, Aldershot: Ashgate.

Miraftab, F. (2004). "Public-Private Partnerships. The Trojan Horse of Neoliberal Development?", Journal of Planning Education and Research, 24(1), 89-101.

Moulaert, F., F. Martinelli, S. Gonzales \& E. Swyngedouw (2007). "Introduction: Social Innovation and Governance in European Cities: Urban Development between Path Dependency and Radical Innovation", European Urban and Regional Studies 14,195-209.

Osei-Kyei, R., \& Chan, A.P. (2015). "Reviews of Studies on the Critical Success Factors for PublicPrivate Partnership (PPP) Projects from 1990 to 2013", International Journal of Project Management, 33, 1335-1346.

Palcic, D., \& Reeves, E. (2011). "Privatization, Employee Share Ownership and Governance: The Case of EIRCOM", Annals of Public and Cooperative Economics, 82(4), 437-454.

Pierre, J. (1999). "Models of Urban Governance: Institutional Dimension of Urban Politics", Urban Affairs Review 34, 372-396.

Putri, R. ve Wirahadikusumah, R.D. (2019). "Readiness of Local Government in PPP Project Development - Case of LRT Bandung", MATEC Web of Conferences 270, 05002, https://doi.org/10.1051/matecconf/201927005002.

Roberts, A. (2010). The Logic of Discipline: Global Capitalism and The Architecture of Government, Oxford: Oxford University Press.

Rogerson, R., \& Boyle, M. (2000). "Property, Politics and The Neoliberal Revolution in Urban Scotland", Progress in Planning, 54(3), 133-196.

Sagalyn, L. B. (2007). "Public/Private Development. Lessons from History, Research and Practice", Journal of the American Planning Association, 73(1), 7-22.

Sager, T. (2011). "Neo-Liberal Urban Planning Policies: A Literature Survey 1990-2010”, Progress in Planning 76, 147-199.

Santos Junior, O. A. (2017). "Entrepreneurial Governance: Neoliberal Modernization”, Luiz Cesar de Queiroz Ribeiro Ed., Urban Transformations in Rio de Janeiro, 273-286.

Sclar, E. (2015). The Political Economics of Investment Utopia: Public-Private Partnerships for Urban Infrastructure Finance, Journal of Economic Policy Reform, 18(1), 1-15. 
Shin, H. B. (2009). "Residential Redevelopment and the Entrepreneurial Local State: The İmplications of Beijing's Shifting Emphasis on Urban Redevelopment Policies", Urban Studies, 46, 2815-2839.

Siemiatycki, M. (2007). "What's The Secret? Confidentiality in Planning Infrastructure Using Public/Private Partnerships", Journal of the American Planning Association, 73(4), 388403.

Siemiatycki, M. (2010). "Delivering Transportation Infrastructure through Public-Private Partnerships: Planning Concerns", Journal of the American Planning Association, 76(4), 43-58.

Siemiatycki, M. (2013). "Public-Private Partnerships in Mega-Projects: Successes and Tensions", In H. Premus, \& B.V. Wee (Eds.), International Handbook On Mega-Projects, Cheltenham: Edward Elgar, 133-157.

Smitha, K. C. (2017). "Entrepreneurial Urbanism in India: A Framework", Entrepreneurial Urbanism in India The Politics of Spatial Restructuring and Local Contestation, Ed. Kanekanti Chandrashekar Smitha, ISBN 978-981-10-2235-7 ISBN 978-981-10-2236-4 (eBook) DOI 10.1007/978-981-10-2236-4, 1-17.

Soomro, M.A., \& Zhang, X. (2013). "Roles of Private-Sector Partners in Transportation PublicPrivate Partnership Failures", Journal of Management in Engineering, http:// Dx.Doi.Org/10.1061/(ASCE)ME.1943-5479.0000263, 31(4).

Swyngedouw, E. (2005). "Governance Innovation and the Citizen: The Janus Face of Governancebeyond- State". Urban Studies 42, 1991-2006.

Swyngedouw, E., F. Moulaert \& A. Rodriguez (2002a). "Neoliberal Urbanization in Europe: Largescale Urban Development Projects and the New Urban Policy", In: N. Brenner\&N. Theodore eds., Spaces of Neoliberalism: Urban Restructuring in North America and Western Europe, Malden, MA: Blackwell, 195-229.

Swyngedouw, E., F. Moulaert \& A. Rodriguez (2002b). "Neoliberal Urbanization in Europe: Largescale Urban Development Projects and the New Urban Policy", Antipode 34, 542-575.

Taşan-Kok, T. (2010). "Entrepreneurial Governance: Challenges of Large-Scale Property-Led Urban Regeneration Projects", Tijdschrift voor Economische en Sociale Geografie, 101(2), 126149.

Theodore N, Peck J, Brenner N (2009). "Urbanismo Neoliberal: la Ciudad y el İmperio de los Mercados", Temas sociales, 66.

Van Ham, H., \& Koppenjan, J. (2001). "Building Public-Private Partnerships: Assessing and Managing Risks in Port Development”, Public Management Review, 4(1), 593-616.

Zheng, J. (2011). “Creative Industry Clusters' and the 'Entrepreneurial City' of Shanghai”, Urban Studies, 48, 3561-3582.

\section{SUMMARY}

Along with the neoliberalism, local policy practices were also affected by the limitation of the public sector and increasing international capital mobility. In this process, the transition to the forms of entrepreneurial governance means the use of PPPs as an alternative service delivery method in the provision of public services. In local services, there is an increasing interest in both public private sector cooperation (PPP) and entrepreneurship capability. PPPs provide support mechanisms that are easily accessible and adapted to their needs by local businesses. These collaborations are considered to be one of the effective ways of local financing as they bring together local authorities, the financial sector and nonprofit organizations to optimize their funding programs.

In this study, the importance of PPPs for local entrepreneurship and the complexity of the PPPs management dimensions were analyzed. Local projects are very complex because they contain more than one player with different 
expectations. This requires the existence of governance regimes at the local or regional level. This study focuses on how the complexities of multiplayer governance affect the implementation of local projects with a theoretical view.

In developed societies, the number of actors in the planning process has increased. This is because the problem and the preferred solution are interdisciplinary. This approach envisages the emergence of sub-systems that form the complex and indirectly connected to each other for urban and regional development. Systems with subsets with indirect links produce highly complex and unpredictable results.

It is not certain that pre-defined, planned and coordinated forms of governance will be realized in entrepreneurial governance. Even though the main items on the policy agenda are handled by the local government, especially if there is an opportunity for development related to property-based development projects, the agenda items will come to the fore. If the enterprise system cannot cope with the difficulties in the policy implementation process, the governance system will be solved.

The conflict between the objectives of various private and public sector stakeholders is a common feature of multi-actor projects. This is because the reconciliation and the balancing of interests require time and energy. This increases the cost for each stakeholder. In addition, there is a need for a change of emphasis in social innovation in order to provide services to low-income people. The provision of such services creates a conflict between public and private sector actors as it is not on the private sector agenda. In addition, the objectives of the parties as a result of changing market conditions and externalities will also change over time. This makes the entire process more complex. Each actor has his own goals and priorities. These may differ during large projects. Because of this, it is difficult to concentrate the actors on the main objective of the project.

As a result, new governance modes in large-scale projects point to a shift from political elite-oriented processes to elite-oriented processes. The resourcestricken local governments are hoping to improve the quality of the public service and to save costs by making use of the expertise and strengths of the private sector by making the PPPs a new service for public service delivery. However, the benefits of PPPs cannot be guaranteed much. 